Kansas State University Libraries

New Prairie Press

\title{
ESTIMATION OF AND ADJUSTMENT FOR RESIDUAL EFFECTS IN DAIRY FEEDING EXPERIMENTS UTILIZING CHANGEOVER DESIGNS
}

Ramon C. Littell

Charles J. Wilcox

H. H. Van Horn

A. P. Tomlinson

See next page for additional authors

Follow this and additional works at: https://newprairiepress.org/agstatconference

Part of the Agriculture Commons, and the Applied Statistics Commons

\section{(c) (1) $\Theta($}

This work is licensed under a Creative Commons Attribution-Noncommercial-No Derivative Works 4.0 License.

\section{Recommended Citation}

Littell, Ramon C.; Wilcox, Charles J.; Van Horn, H. H.; and Tomlinson, A. P. (1995). "ESTIMATION OF AND ADJUSTMENT FOR RESIDUAL EFFECTS IN DAIRY FEEDING EXPERIMENTS UTILIZING CHANGEOVER DESIGNS," Conference on Applied Statistics in Agriculture. https://doi.org/10.4148/2475-7772.1336

This is brought to you for free and open access by the Conferences at New Prairie Press. It has been accepted for inclusion in Conference on Applied Statistics in Agriculture by an authorized administrator of New Prairie Press. For more information, please contact cads@k-state.edu. 
Author Information

Ramon C. Littell, Charles J. Wilcox, H. H. Van Horn, and A. P. Tomlinson 


\title{
ESTIMATION OF AND ADJUSTMENT FOR RESIDUAL EFFECTS IN DAIRY FEEDING EXPERIMENTS UTILIZING CHANGEOVER DESIGNS ${ }^{1}$
}

\author{
Ramon C. Littell \\ Statistics Department \\ and \\ Charles J. Wilcox \\ H. H. (Jack) Van Horn \\ A. P. Tomlinson \\ Department of Dairy \& Poultry Sciences \\ University of Florida \\ Gainesville Florida 32611-0920 \\ U.S.A.
}

\begin{abstract}
A procedure is presented which demonstrates estimation of and adjustment for residual effects in changeover designs. The method utilizes all data collected in an experiment by including treatments imposed on animals prior to initiation of data collection. Estimation is achieved via general linear models. An example is given of a nutrition experiment conducted with dairy cattle. Such analyses should increase efficacy of changeover designs and reduce concern by researchers about biased estimates of direct effects which could result from residual effects. Methods from popular computer programs for estimating direct effect treatment means are compared. Practical problems encountered in computing standard errors of mean estimates in mixed linear models.
\end{abstract}

\section{INTRODUCTION AND LITERATURE REVIEW}

Changeover designs are widely used in dairy cattle nutrition experiments. This family of designs includes those called Latin Squares, reversals, round-robins, switchbacks, rotational et al. The principal concept in changeover designs is that they permit comparisons of treatments on a within-animal basis because different treatments are assigned to the same animal in sequence. This is in contrast to so-called "continuous designs" in which animals receive the same treatment throughout the study. The coefficients of variation representing error terms used to test effects of interest in dairy nutrition experiments in changeover designs often are only 10 to $40 \%$ as large as those for continuous designs (Wilcox and Van Horn, 1990). Hence changeover designs are preferred over continuous designs whenever they are

${ }^{1}$ Florida Agricultural Experiment Station Journal Series No. R03753. 
appropriate. At least two major disadvantages are associated with changeover designs, however; (1) interactions between main effects often are not estimable, and (2) residual or carryover effects may bias estimates of main or direct effects. Many dairy scientists avoid the use of changeover designs because of their fear that estimates of effects of interest will be biased by residual effects.

Strategies to avoid bias in estimates of direct effects, arising from residual effects, include (Cochran and Cox, 1962; Damon and Harvey, 1987): (1) lengthen periods so that residual effects tend to dissipate and analyze only data from the latter part of the period; (2) use balanced designs so that residual effects tend to cancel out; and (3) use designs which permit the estimation of and adjustment for residual effects. The latter often require addition of an extra period (Lucas, 1974).

Estimation of direct and residual effects can be accomplished without addition of an extra period, however (Becerril and Garza, 1986; Littell, Freund, and Spector, 1991). In such designs residual effects appear only in period two and subsequent periods since period one treatments do not follow other treatments. An assumption thus is made that no residual effects occur which originate in period one. Becerril and Garza (1986) and Littell, Freund, and Spector (1991) showed how estimates of residual effects are easily obtained by fitting general linear models using PROC GLM in the SAS System (SAS Inst. Inc., 1982). However, at times some of the treatments which are used in the experiment also are used during period zero, the preliminary or standardization period. For the procedure reported here, the standardization period treatments must appear as treatments during subsequent periods.

In the present paper a dairy feeding trial is used to illustrate the design and analysis procedure for estimation of residual effects and for adjusting treatment direct effects to remove bias from the residual effects. Then four statistical estimation procedures from well-known computer programs are discussed, comparing standard errors for the various statistical procedures. Issues involved in computing appropriate standard errors also are discussed.

\section{METHODS AND MATERIALS}

The experimental design of the dairy study was an incomplete Latin Square partially balanced for residual effects. Assignment of treatments to animals followed a schedule similar to that of Roman et al. (1975). The experiment was conducted at the University of Florida Agricultural Experiment Station Dairy Research Unit at Hague, FL. Details of the design and results and description of the experiment are provided in Tomlinson et al. (1994).

Thirty-six Holstein cows were assigned to treatment sequences over four 28-day periods. There were 12 treatments consisting of combinations of Ca soaps of long-chain fatty acids (as fat source) and several protein diets, described by Tomlinson et al. (1994).

Numerous milk quantity and quality variables and animal performance variables were recorded and analyzed, but only milk yield will be discussed extensively here. Values for response variables were used only from the latter 14 days of each period. For milk yield (MY) and solids-corrected milk yield (SCM), data from the last 7 days of each period also were analyzed. Thus two of the three strategies for reducing biases in estimates of residual effects were evoked, although only partial balance was achieved. 
For 14 days prior to the initiation of the experiment (denoted period zero), cows were assigned and subjected to one of the 12 treatments. Measurements of the response variables were not made during this period. At the end of period zero, cows were assigned to a different treatment to begin their four-period sequence of treatments. Thus each cow received four of the 12 treatments during the comparison periods (1 through 4) and a fifth during the standardization (period 0) period. Data from three cows were excluded because of cow health problems, leaving 33 cows of which 22 were multiparous and 11 were primiparous.

Data were analyzed by least squares analysis of variance using the Harvey LSMLMW computer program (Harvey, 1990). The statistical model included group (multi- or primiparous), cow within group, period, treatment (the direct effect), previous treatment (the residual effect), group by treatment interaction, and group by previous treatment interaction as shown in Table 1. Previous treatment was the treatment assigned to each cow in the period immediately preceding the period of measurement. Estimates of these effects, therefore, represent residual (carryover) effects. Dry matter intake (linear) was included as a continuous independent variable. Random effects were cow within group and remainder; all other effects were considered fixed.

Models for Crossover Designs. A mathematical model for the usual type of changeover design (in which no treatment is given in period zero) with a between-animal grouping variable and within-animal treatment variable is

$$
\mathrm{Y}_{\mathrm{ijklm}}=\mu+\alpha_{\mathrm{i}}+\mathrm{d}_{\mathrm{ij}}+\beta_{\mathrm{k}}+\tau_{\mathrm{l}}+\gamma_{\mathrm{m}, \mathrm{k}-1}+\mathrm{e}_{\mathrm{ijklm}}
$$

where $\mu=$ reference mean, $\alpha_{\mathrm{i}}=$ effect of $\mathrm{i}^{\text {th }}$ group, $\mathrm{d}_{\mathrm{ij}}=$ effect of $\mathrm{j}^{\text {th }}$ animal in $\mathrm{i}^{\text {th }}$ group, $\beta_{\mathrm{k}}$ $=$ effect of $\mathrm{k}^{\text {th }}$ period, $\tau_{1}=$ direct effect of $\mathrm{l}^{\text {th }}$ treatment, $\gamma_{\mathrm{m}, \mathrm{k}-1}=$ residual effect of treatment $\mathrm{m}$ in period $\mathrm{k}-1$, and $\mathrm{e}_{\mathrm{ijklm}}=$ random error. (Since only residual effects from the previous period are considered possible, the subscript $\mathrm{k}-1$ on the residual effect $\gamma_{\mathrm{m}, \mathrm{k}-1}$ is redundant. Also, interactions are not included for sake of simplicity and the fact that none were significant in the dairy feeding experiment.) All effects are considered fixed except $\mathrm{d}_{\mathrm{ij}}$ and $\mathrm{e}_{\mathrm{ijklm}}$, which are taken to be normally and independently distributed with variances $\sigma_{\mathrm{d}}^{2}$ and $\sigma_{\mathrm{e}}^{2}$, respectively. It is assumed that $\gamma_{\mathrm{m}, 0}=0$, due to there being no treatment in period 0 . In terms of model (2.1), the direct effect mean for treatment 1 in group i, as implicitly defined by Cochran and Cox (1957), is given by

$$
\mu_{\mathrm{li}}=\mu+\alpha_{\mathrm{i}}+\beta+\tau_{1}+\gamma
$$

where $\beta$ stands for the average period effect and $\gamma$ stands for the average residual effect. In some applications it may be more meaningful to define $\beta$ to be a random effect, such as when periods serve as replication over time. But in the present context, periods represent specific times in a lactation, and thus are meaningfully defined as fixed. Also, note that no 
assumptions for estimability are made on the treatment direct effect or residual effect parameters. This is why $\gamma$ appears in the expression for the treatment direct mean as the average residual effect. Cochran and Cox (1957, pg. 137) compute direct and residual effects to sum to zero. If the model (2.1) were parametrized with corresponding conditions on the parameters, then $\gamma$ would be zero, and thus would not appear in the expression for the direct mean. In the dairy feeding experiment described here, one of the treatments was a control, so it is more meaningful to define the treatment direct and residual effects of that treatment to be zero. These are technical side issues, and will not be discussed further in order not to distract from the main topics of the paper.

The model described in the preceding paragraph with equation (2.1) is an example of the general linear mixed model (GLMM). Its parameters can be estimated using a variety of estimation techniques, including least squares and maximum likelihood. Estimates of the direct treatment effects and the residual effects are unbiased using either least squares or maximum likelihood. In this sense, treatment direct effect means can be estimated free of residual effects. It is not necessary that the experimental design be balanced in any particular way for the estimates to be unbiased. The designs discussed by Cochran and Cox (1957, section 4.6a) are balanced, and analyses are amenable to hand computation. The example analysis in section 4.62a of Cochran and Cox (1957) was reproduced using PROC GLM of the SAS System by Littell, Freund and Spector (1991, pg. 205). The CLASS statement in PROC GLM sets up appropriate definitions of dummy variables in model (2.1) except for the residual effects $\gamma_{\mathrm{m}, \mathrm{k}-1}$, for which dummy variables can be constructed explicitly. The methods given by Littell et al (1991) do not require balance; only estimability of parameters of interest.

A model for a changeover design in which treatments were administered in period 0 also has equation (2.1), but $\gamma_{\mathrm{m}, 0}$ is not assumed to be zero. This also is a GLMM and can be fitted with least squares or maximum likelihood. However, there are numerous versions of least squares and maximum likelihood represented in various computer programs, and all give somewhat different results. The central issue is the manner in which to deal with random effects. In the remainder of this section some of the possibilities are described.

Methods for Fitting Models. First of all, for the data set at hand there was no evidence of residual effects, so an argument could be made to delete $\gamma_{\mathrm{m}, \mathrm{k}-1}$ from the model. The question of which method of estimation to use to deal with the random effect is equally relevant without the residual effects in the model. However, for the sake of completeness, residual effect parameters are retained in the model

$$
\mathrm{Y}_{\mathrm{ijklm}}=\mu+\alpha_{\mathrm{i}}+\mathrm{d}_{\mathrm{ij}}+\tau_{1}+\gamma_{\mathrm{m}, \mathrm{k}-1}+\mathrm{e}_{\mathrm{ijklm}} \text {. }
$$

All terms in this model are as defined in equation (2.1) except $\gamma_{\mathrm{m}, 0}$ is not assumed to be zero. The objective is to estimate the treatment direct effect means (averaged over parity group) 


$$
\mu_{1}=\mu+\alpha+\beta+\tau_{1}+\gamma
$$

where $\alpha$ stands for the average group effect.

Model 2.2 can be rewritten to include only the fixed effects plus the conglomeration of random effects as

$$
\mathrm{Y}_{\mathrm{ijklm}}=\mu+\alpha_{\mathrm{i}}+\beta_{\mathrm{k}}+\tau_{1}+\gamma_{\mathrm{m}, \mathrm{k}-1}+\epsilon_{\mathrm{ijklm}},
$$

where $\epsilon_{\mathrm{ijklm}}=\mathrm{d}_{\mathrm{ij}}+\mathrm{e}_{\mathrm{ijklm}}$ from 2.2. Of course, the $\epsilon_{\mathrm{ijklm}}$ terms are not independent.

Four methods of estimation will be described in terms of computer programs that implement them. The methods will be referred to as GLM II, GLM III, HARVEY, and MIXED.

GLM II: OLS (ordinary least squares) estimation of parameters in model 2.4. Estimates may be obtained from SAS GLM using the statements

proc glm; class grp per trt pretrt; model my = grp per trt pretrt; Ismeans trt;

run;

GLM III: OLS estimation of all terms in model 2.2, including random effects of cow. Estimates may be obtained from SAS GLM using the statements

proc glm; class grp cow per trt pretrt; model my $=$ grp cow(grp) per trt pretrt; Ismeans trt; run;

HARVEY: Same estimates as GLM III. Estimates may be obtained from Harvey's LSMLMW and MIXMDL using statements

classes grp cow per trt; model3 my = grp cow:grp per trt pretrt/listparm;

MIXED: GLS (estimated generalized least squares) estimates of fixed effect parameters in model 2.2, using estimates of variance components in covariance matrix. Estimates may be obtained from SAS MIXED using the statements

proc mixed; class grp cow per trt pretrt; model my = grp per trt pretrt; 


\author{
random cow(trt); \\ Ismeans trt; \\ run;
}

\title{
3. RESULTS AND DISCUSSION
}

In no instance were residual effects detected overall treatments (Table 1). Mean probability level for the eight responses was .537; range was .145 to .928. The latter value was for milk yield. Of 88 orthogonal contrasts for residual effects (eight response variables with 11 d.f. each), only six were significant at $\mathrm{P}<.10$ and two at $\mathrm{P}<.05$.

For eight interactions between group and residual effects, range of probability levels was .087 to .771 , averaging .354. Probability for milk yield was .771 . Thus it appears that there was no evidence for presence of a parity group by residual effects interactions.

Researchers in dairy cattle nutrition may have been unduly concerned about presence of residual effects in experiments of similar nature. In any event, had residual effects occurred, their magnitude and statistical significance would have been estimated, and their effects on direct effects removed.

Coefficients of variation based on error variances and arithmetic means for the eight responses are in Table 1 . They ranged from $1.7 \%$ for body weight change to $17.0 \%$ for fat percentage. Value for milk yield was $6.2 \%$. Values for MY4 and SCM4 were expected to be slightly larger than those for MY and SCM, since they were based on data from 7 rather than 14 days. They were not, however; one was slightly larger and one was slightly smaller than its counterpart.

Effects of adjustment of treatment means for residual effects are shown in Table 2 for milk yield. Largest adjustment was $1.1 \mathrm{lb}$ for treatment 6 . Selected orthogonal contrasts for treatment effects, adjusted or not adjusted for residual effects, along with the same contrasts for the residual effects, are in Table 3. Overall variation in treatment effects was significant $(\mathrm{P}<.020)$ for milk yield before adjustment, but not significant $(\mathrm{P}<.140)$ after adjustment. The adjustment itself was not significant $(\mathrm{P}<.928)$. Smith et al. (1993) likewise could not detect residual effects in an experiment with similar design but different treatments.

The procedure illustrated is appropriate for this family of experimental designs. It is accomplished very easily, requiring that one or more of the treatments used during the course of the experiment be used prior to the experiment. No measurements of the response variables are necessary prior to the experiment.

Residual effects were not detected in this experiment, suggesting either that none existed, or that the strategy of using only data in the analysis from the latter part of the period was effective. Adjustments of treatment means were small, reflecting the small magnitude of the residual effects as well as the partial balance of the design.

Because of relatively small error variance in changeover designs compared to continuous trials, the former should be used wherever appropriate without undue concern for residual effects. If residual effects are not detected in an experiment, they can be deleted from the mathematical model and the analysis performed without them. The presence or absence of residual effects in itself is a noteworthy finding in experiments of this nature. 
Results presented so far were obtained from Harvey's LSMLMW and MIXMDL programs. In particular, LSMeans in the first and second columns of Table 2 are estimates of treatment direct effect means without and with, respectively, residual effects in the model. Remaining results pertain to comparisons of the four estimation methods defined in the previous section.

Direct effect means for the 12 treatments using each of the estimation methods are presented graphically in Figure 1. As noted in the previous section, the numerical values of the treatment direct effect means will be identical from GLM III and HARVEY, so that only three distinct sets of means are shown. Note that the GLM II means differ more from treatment to treatment than do the GLM III/HARVEY or the MIXED means. The GLM III/HARVEY and the MIXED means are similar across the treatments.

Standard Errors of Treatment Direct Effect Means. Various problems are encountered when computing standard errors of parameter estimates in mixed models. This is true for the four estimation methods presented in the previous section. First of all, PROC GLM in the SAS System computes standard errors strictly on the basis of OLS, treating all effects in the MODEL statement as if they are fixed. Parameter estimates computed by GLM are linear functions of the data; that is, they are of the form $\mathbf{a}^{\prime} \mathbf{Y}$ where $\mathbf{Y}$ is the vector of observed data. Thus the correct standard error of an estimate computed by GLM is of the form $\left(c_{d} \sigma_{d}^{2}+c_{e} \sigma_{e}^{2}\right)^{1 / 2}$. But the standard error computed by GLM for the estimate is $\left(c_{e} M S E\right)^{1 / 2}$, where MSE is the residual mean square from the fitted model. If all random effects are contained in the MODEL statement, then MSE estimates $\sigma_{\mathrm{e}}^{2}$. Therefore, the standard error computed by GLM will be too small because it estimates $\left(c_{e} \sigma_{e}^{2}\right)^{1 / 2}$. This is the case with GLM III standard errors printed by GLM, which are shown in Figure 2. If random effects are deleted from the model, then those sources of variation will be dumped into residual variation. Consequently, the residual mean square MSE will estimate $c \sigma_{d}^{2}+\sigma_{e}^{2}$ for some constant c. Therefore, the standard error computed by GLM will estimate $\left(c_{e}\left(c \sigma_{d}^{2}+\sigma_{e}^{2}\right)\right)^{1 / 2}$, which can be either too large or too small. This is the case with GLM II estimates; the printed standard errors can either over- or under-estimate the correct standard error.

Standard errors for GLM II estimates shown in Figure 2 have the residual mean square factored out and replaced by the residual mean square from the GLM III model in order to make them directly comparable. That is, Figure 2 shows estimates of $\left(\mathrm{c}_{\mathrm{II}, \mathrm{e}} \sigma_{\mathrm{e}}^{2}\right)^{1 / 2}$ and $\left(\mathrm{c}_{\mathrm{III}, \mathrm{e}} \sigma_{\mathrm{e}}^{2}\right)^{1 / 2}$ for GLM II and GLM III, respectively, where $\mathrm{c}_{\mathrm{II}, \mathrm{e}}$ and $\mathrm{c}_{\mathrm{III}, \mathrm{e}}$ are the coefficients of $\sigma_{e}^{2}$ in the correct standard errors of the form $\left(c_{d} \sigma_{d}^{2}+c_{e} \sigma_{e}^{2}\right)^{1 / 2}$ for the GLM II and GLM III estimates. Therefore, GLM II standard errors in Figure 2 are all smaller than the GLM III standard errors because the model for GLM II (2.4) has fewer terms in it than the model for GLM III (2.2), with the result that $\mathrm{c}_{\mathrm{II}, \mathrm{e}}<\mathrm{c}_{\mathrm{III}, \mathrm{e}}$.

Standard errors for GLM II and GLM III estimates can be estimated using linear combinations of the variance components and replacing the variance components by their 
estimates. The first step is to obtain the coefficients $\mathrm{c}_{\mathrm{II}, \mathrm{d}}$ and $\mathrm{c}_{\mathrm{III}, \mathrm{d}}$, and $\mathrm{c}_{\mathrm{II}, \mathrm{e}}$ and $\mathrm{c}_{\mathrm{III}, \mathrm{e}} \cdot$ This can be done in an indirect manner as illustrated by Milliken and Johnson (1981) and extended by Littell and Linda (1990). The coefficient $\mathrm{c}_{\mathrm{II}, \mathrm{d}}$ requires one preliminary step, however, to compute the expected mean square $E\left(\ell^{\prime} Y / \ell^{\prime} \ell\right)$ for the linear combination $\ell^{\prime} Y$, where $\ell^{\prime} Y$ stands for a linear combination of the data vector equal to a GLM II LSMean. The method of synthesis (Hartley, 1967) may be used to compute the required coefficients. The next step is to choose estimates of the variance components $\sigma_{\mathrm{d}}^{2}$ and $\sigma_{\mathrm{e}}^{2}$. Standard errors obtained by this procedure, utilizing REML estimates of the variance components, are presented in Figure 3. The standard errors for both GLM II and GLM III estimates are much larger than those in Figure 2 due to incorporating the between-cow variance component $\sigma_{d}^{2}$. The ones in Figure 3 can be regarded as "correct" standard errors in that they contain the correct combinations of variance components.

Standard errors for HARVEY mean estimates are presented in Figure 4. These are printed directly by Harvey's LSMLMW program. Recall that the GLM III and HARVEY LSMeans estimates are identical and therefore the correct standard error of HARVEY estimates is also $\left(\mathrm{c}_{\mathrm{III}, \mathrm{d}} \sigma_{\mathrm{d}}^{2}+\mathrm{c}_{\mathrm{III,e}} \sigma_{\mathrm{e}}^{2}\right)^{1 / 2}$. The standard errors printed by LSMLMW differ from the standard errors displayed for GLM III estimates in Figure 3 only due to LSMLMW using ANOVA estimates of the variance components instead of REML. In the present example, the REML estimates are slightly smaller than the ANOVA estimates, but this would not be the case in general. Standard errors of MIXED estimates shown in Figure 4 indicate that MIXED estimates have smaller standard errors than the GLM III/HARVEY estimates. True GLS estimates would have smaller standard errors than any of the other estimates considered here because they are BLUE. This results in the MIXED standard errors in Figure 4 being uniformly smaller than the GLM III standard errors because both have actual variance components replaced by REML estimates.

There is another issue concerning computation of standard errors for the MIXED estimates. While computed standard errors for MIXED estimates take appropriate account of the presence of random effects, they do not take account of the fact that variance components in the covariance matrix $\mathbf{V}$ are replaced by their estimates. That is, MIXED estimates of fixed effects are not really GLS, but rather estimated GLS (EGLS). Consequently, standard errors of MIXED estimates will be too small, i.e., biased downward. This is a phenomena studied by Kackar and Harville (1984). The amount of downward bias is not easily determined analytically. However, a good indication of the amount of bias can be obtained by computer simulation of MIXED estimates using randomly generated data based on distributions obtained from the variance component estimates. The simulated data can be passed through PROC MIXED to compute MIXED estimates which are then stored in a SAS data set. Standard errors are computed as standard deviations of the simulated MIXED estimates. Results from this type of simulation study based on parameter estimates from the dairy cattle nutrition experiment are present in Figure 5. These results reveal that bias in the MIXED standard 
error estimates are negligible in relation to random variation of the standard error estimates. This is not always the case, however, and must be investigated in each situation.

Objectives of the work presented here were twofold: 1) to show how residual effects can be estimated from all data collected, including that in period one, and estimates of direct effects adjusted for them, and 2) to compare estimates of standard errors of estimates of direct effect means resulting from various estimation methodologies.

\section{ACKNOWLEDGMENTS}

The authors gratefully acknowledge contributions of Dr. W. A. Smith, Dept. Anim. Sci., Univ. Stellenbosch, Stellenbosch 7600, South Africa.

\section{LITERATURE CITED}

Becerril, C.M., P., and A.M. Garza. 1986. Disenos cruzados en cuadro Latino con efectos residuales. Sob. de Agron. 65:203.

Cochran, W.G., and G.M. Cox. 1962. Experimental Designs. (2nd edition). John Wiley and Sons, New York. p. 133-139.

Damon, R.A. Jr., and W.R. Harvey. 1987. Experimental Design, ANOVA, and Regression. Harper and Row, New York, p. 303-308.

Hartley, H.O. 1967. Espectations, variances and covariances of ANOVA mean squares by "synthesis." Biometrics 23:105; Corrigenda, 853.

Harvey, W.R. 1990. User's guide for LSMLMW and MIXMDL. Mimeo, Ohio State Univ., Columbus. 91p.

Kackar, R.N. and D.A. Harville. 1984. Approximations for standard errors of estimators of fixed and random effects in mixed lniear models. J. Am. Stat. Assoc. 79:853-862.

Littell, R.C., R.J. Freund, and P.C. Spector, P.C. 1991. SAS System for Linear Models. SAS Institutue Inc., Cary, NC. p. 205-209.

Littell, R.C. and S.B. Linda. 1990. Computation of variances of functions of parameter estimates for mixed models in GLM. Proceedings, SAS User's Group International. 1331-1338.

Lucas, H.L. Jr. 1974. Design and analysis of feeding experiments with milking dairy cattle. North Carolina State Univ. Instit. Stat., Mimeo Series 18. Raleigh. Chap. 17, 18.

Milliken, G.A., and D.E. Johnson. 1984. Analysis of Messy Data. Lifetime Learning. Belmont, CA. p. 397-407.

Roman-Ponce, H., H.H. Van Horn, S.P. Marshall, C.J. Wilcox, and P.F. Randel. 1975. Complete rations for dairy cattle. V. Interaction of sugarcane bagasse quantity and form with soybean meal, urea and starea. J. Dairy Sci. 58:1320.

SAS Institute Inc. (1982). SAS Users Guide. Statistics, Cary, North Carolina. p. 205-209.

Smith, W.A., B. Harris, Jr., H.H. Van Horn, and C.J. Wilcox. 1993. Effects of forage type on production of dairy cows supplemented with whole cottonseed, tallow and yeast. J. Dairy Sci. 76:1558. 
Tomlinson, A.P., H.H. Van Horn, C.J. Wilcox, and B. Harris, Jr. 1994. Effects of undegradable protein and supplemental fat on milk yield and composition and physiological responses of cows. J. Dairy Sci. 77:145.

Wilcox, C.J., and H.H. Van Horn. 1990. Experimental designs in dairy cattle nutrition. Ruminant Nutrition: Methods of Investigation. Ed. M.E. Ruiz and A. Ruiz. IICA/RSIPAL. San Jose, Costa Rica. p. 299-310. 
Table 1. Least squares analysis of variance for response variables.

\begin{tabular}{|c|c|c|c|c|c|c|c|c|c|c|}
\hline \multirow[b]{2}{*}{$\begin{array}{l}\text { Source of } \\
\text { variation }\end{array}$} & \multirow[b]{2}{*}{$\mathrm{df}$} & \multirow[b]{2}{*}{$\begin{array}{l}\text { Error } \\
\text { term }\end{array}$} & \multicolumn{8}{|c|}{ Mean Squares } \\
\hline & & & $\begin{array}{l}\text { Milk } \\
\text { yield }\end{array}$ & $\begin{array}{c}\text { Milk } \\
\text { yield44 }\end{array}$ & Fat $\%$ & Prot $\%$ & SCM & SCM4 & $\begin{array}{l}\text { Body weight } \\
\text { change }\end{array}$ & $\begin{array}{l}\text { Body } \\
\text { cond. }\end{array}$ \\
\hline Group, G & 1 & $C(G)$ & $1408.4^{* *}$ & $1322.5^{* *}$ & $2.755^{a}$ & .016 & 478.9 & 427.3 & 275.7 & .4009 \\
\hline $\operatorname{Cow}(G)$ & 31 & $E$ & $48.7^{* *}$ & $54.4^{* *}$ & $.830^{* *}$ & $.079^{* *}$ & $111.8^{* *}$ & 121.2 & 42328.1 & $.1605^{\star *}$ \\
\hline Period & 3 & $E$ & $197.3^{* *}$ & $182.1^{\star *}$ & .385 & $.072^{*}$ & $161.6^{* *}$ & 152.6 & 5262.8 & $.3370^{* *}$ \\
\hline Treatment, $T^{1}$ & 11 & $E$ & 21.2 & $20.5^{a}$ & .447 & $.034^{\mathrm{a}}$ & $72.8^{* *}$ & 71.7 & 822.7 & .0121 \\
\hline Residual, $\mathrm{R}^{1,2}$ & 11 & $E$ & 6.0 & 7.0 & .307 & .019 & 31.9 & 33.0 & 668.3 & .0240 \\
\hline$G^{*} T$ & 11 & $E$ & 10.0 & 10.6 & .317 & .012 & 38.5 & 45.2 & 763.3 & .0091 \\
\hline$G * R$ & 11 & $E$ & 8.9 & 14.8 & .448 & $.034^{\mathrm{a}}$ & 34.3 & 39.7 & 626.7 & .0144 \\
\hline Feed Intake & 1 & $E$ & 164.5 & $150.5^{\star *}$ & .058 & .008 & $139.0^{*}$ & 125.2 & 5996.5 & .0015 \\
\hline Error, E & 50 & - & 13.5 & 12.3 & .386 & .019 & 27.2 & 28.5 & 428.4 & .0189 \\
\hline $\begin{array}{l}\text { Coefficient of } \\
\text { variation }(\%)\end{array}$ & - & - & 6.2 & 5.9 & 17.0 & 4.8 & 8.8 & 9.0 & 1.7 & 4.6 \\
\hline
\end{tabular}

1 See Table 3 for selected orthogonal contrasts of treatment and residual effects.

${ }^{2}$ Residual (carry-over) effects from treatments imposed in the period immediately preceding the period of measurement. ${ }^{\star \star} \mathrm{P}<.01 ;{ }^{\star} \mathrm{P}<.05,{ }^{\mathrm{a} P}<.10$.

Table 2. Least squares means for treatment effects adjusted and not adjusted for residual effects: Milk yield (kg).

\begin{tabular}{ccc}
\hline & \multicolumn{2}{c}{ Least squares means $^{\text {Treatment }}$} \\
\cline { 2 - 3 } & Not adjusted $^{1}$ & Adjusted $^{2}$ \\
\hline 1 & 57.7 & 56.9 \\
2 & 54.7 & 53.8 \\
3 & 59.2 & 58.6 \\
4 & 61.0 & 60.3 \\
5 & 57.7 & 58.7 \\
6 & 61.5 & 60.4 \\
7 & 58.8 & 58.7 \\
8 & 60.9 & 60.8 \\
9 & 61.6 & 60.6 \\
10 & 60.4 & 61.3 \\
11 & 59.9 & 60.4 \\
12 & 58.1 & 59.3 \\
\hline
\end{tabular}

1 Treatment effects significant at $P<.020$.

${ }^{2}$ Adjusted treatment effects significant at $P<.140$. See Table 3 for selected orthogonal contrasts.
Table 3. Probability levels associated with selected orthogonal contrasts for treatment and residual effects for milk yield.

\begin{tabular}{|c|c|c|c|}
\hline \multirow[b]{2}{*}{$\begin{array}{l}\text { Orthogonal } \\
\text { contrast }\end{array}$} & \multicolumn{3}{|c|}{ Effects } \\
\hline & Treatment $^{1}$ & Residual $^{2}$ & Treatment $^{3}$ \\
\hline $\begin{array}{l}\text { Control vs. } \\
\text { added fat }\end{array}$ & .746 & .544 & .780 \\
\hline $\begin{array}{l}\text { Crude protein, } \\
\text { linear }\end{array}$ & .001 & .724 & .001 \\
\hline $\begin{array}{l}\text { Crude protein, } \\
\text { quadratic }\end{array}$ & .070 & .469 & .100 \\
\hline $\begin{array}{l}\text { Bone meal vs } \\
\text { feather meal }\end{array}$ & .677 & .304 & .869 \\
\hline \multicolumn{4}{|c|}{$\begin{array}{l}1 \text { Pretreatment deleted from model; overall } \\
\text { probability level for treatment effects, } P<.020(11 \\
\text { d.f.). }\end{array}$} \\
\hline $\begin{array}{l}2 \text { Pretreatment } \\
\text { level for residua } \\
\text { treatment effec }\end{array}$ & $\begin{array}{l}\text { cluded in } \mathrm{mc} \\
\text { effects, } P<.9\end{array}$ & $\begin{array}{l}\text { odel; overa } \\
928 \text { (11 d.f. } \\
\text { d.f.). }\end{array}$ & $\begin{array}{l}\text { I probability } \\
\text {; for }\end{array}$ \\
\hline
\end{tabular}




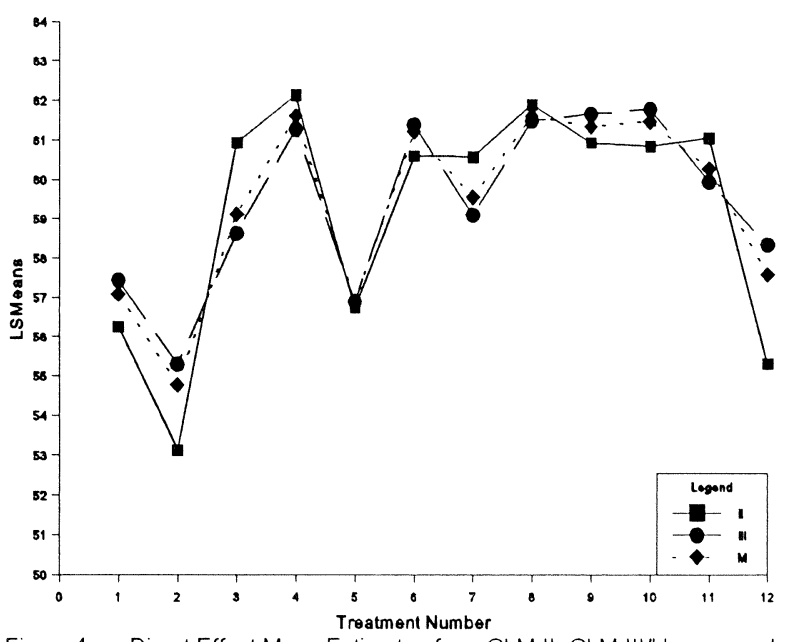

Figure 1. Direct Effect Mean Estimates from GLM II, GLM III/Harvey, and MIXED

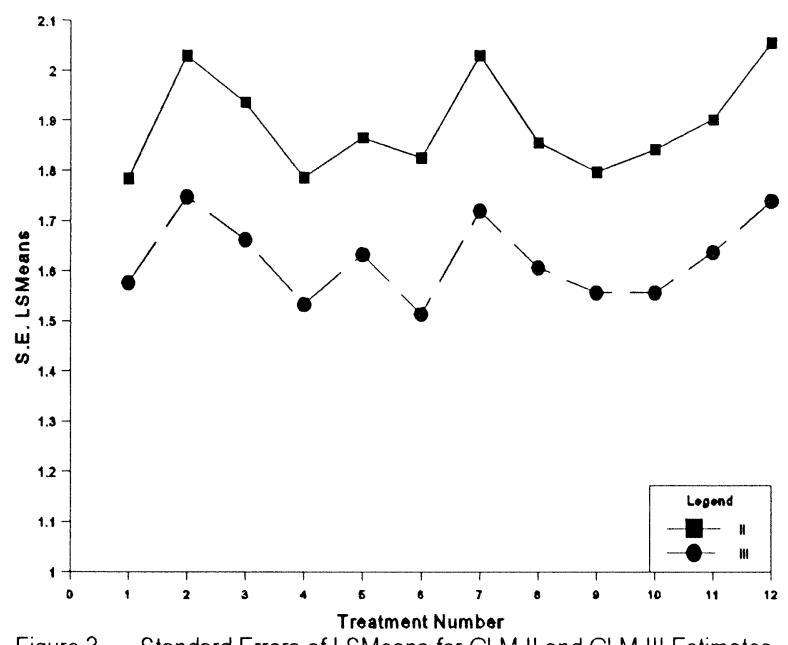

Figure 3. Standard Errors of LSMeans for GLM II and GLM III Estimates Including Random Effects

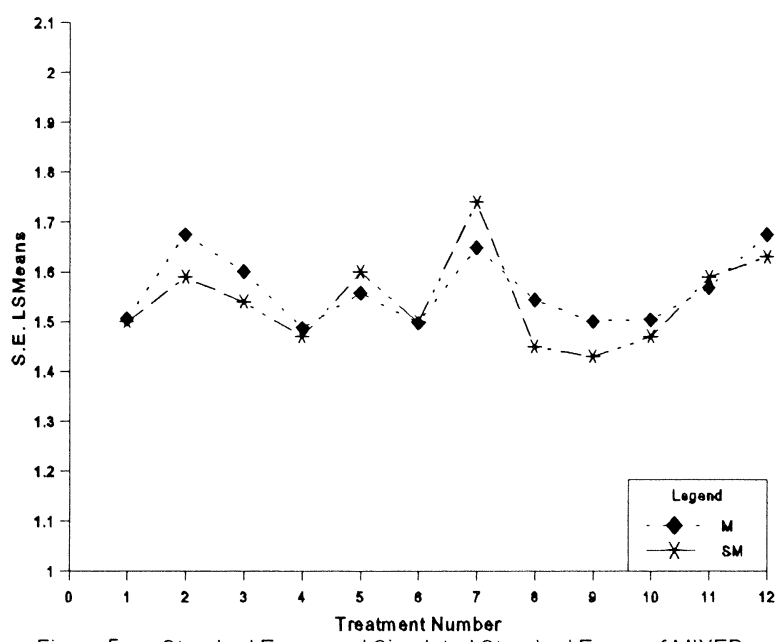

Figure 5. Standard Errors and Simulated Standard Errors of MIXED Estimates

New Prairie Press

https://newprairiepress.org/agstatconference/1995/proceedings/10

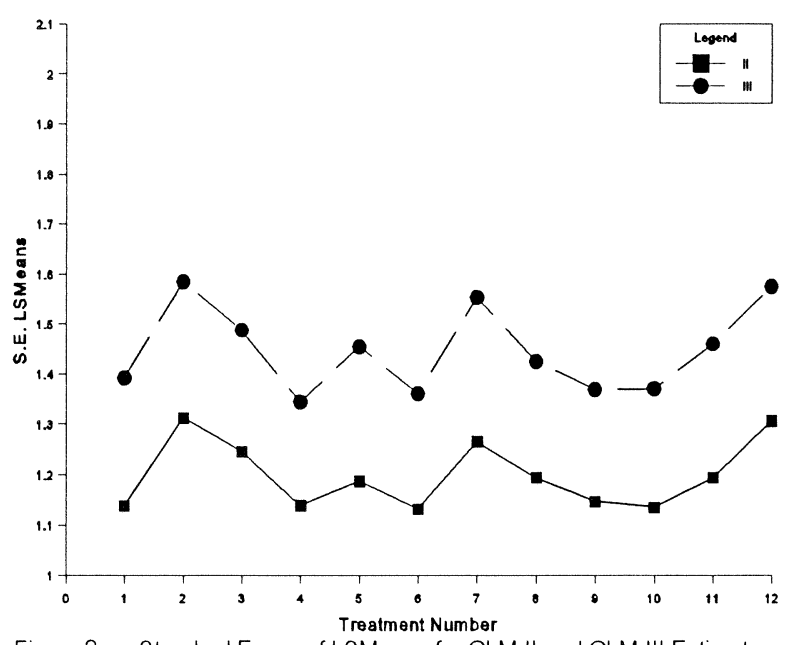

Figure 2. Standard Errors of LSMeans for GLM II and GLM III Estimates Ignoring Random Effects

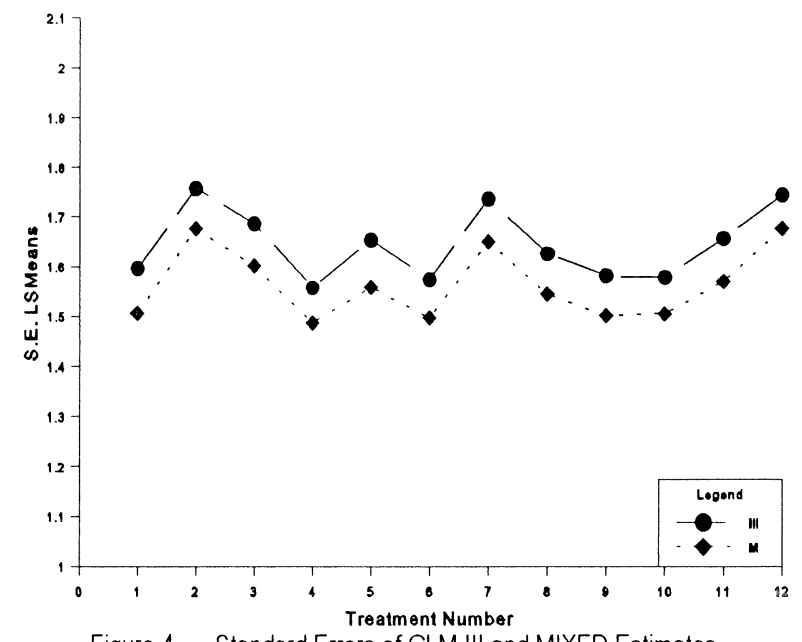

Figure 4. Standard Errors of GLM III and MIXED Estimates 